\title{
Dural arteriovenous fistula and cerebral venous thrombosis
}

\author{
Fístula arteriovenosa dural e trombose venosa cerebral
}

Adriana Bastos Conforto 1,2, Saulo Nardy Nader', Paulo Puglia Junior³, Fabio luji Yamamoto', Marcia Rubia Rodrigues Gonçalves ${ }^{1}$, Fernando Roberto Gondim C. de Vasconcelos ${ }^{1}$, Germana Titoneli dos Santos ${ }^{3}$

A 55-year-old man was admitted with Wernicke's aphasia and history of progressive headache in the past three weeks. Computed tomography showed a temporal lobar hemorrhage, transverse sinus thrombosis and suggested a dural arteriovenous fistula (DAF) (Figure 1). Digital subtraction angiography confirmed the DAF, which was successfully treated with embolization (Figure 2).
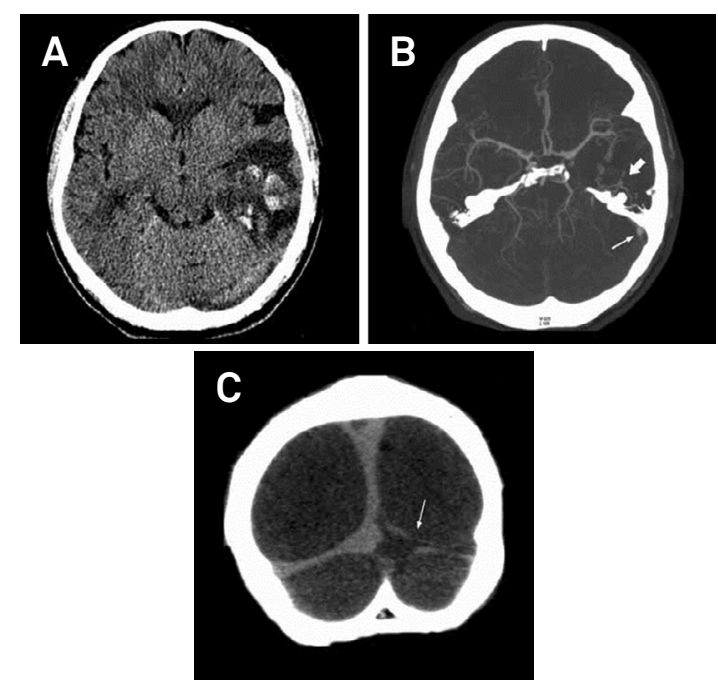

Figure 1. Hematoma in the left temporal lobe identified by computed tomography (CT) (A). CT angiography (CTA, arterial phase, B) showed a vascular structure and early enhancement inside the left sigmoid sinus (thick arrow), as well as serpiginous vessels in the middle cranial fossa (thin arrow). CTA (venous phase, C) showed venous thrombosis (arrow).
DAF is a rare abnormal connection between dural veins and dural or pachymeningeal branches of cerebral arteries. DAF was reported in $1.6 \%$ of patients diagnosed with CVT, which in turn causes $0.5-1 \%$ of all strokes ${ }^{1,2}$. Prompt diagnosis of DAF in patients with CVT is crucial for appropriate treatment.
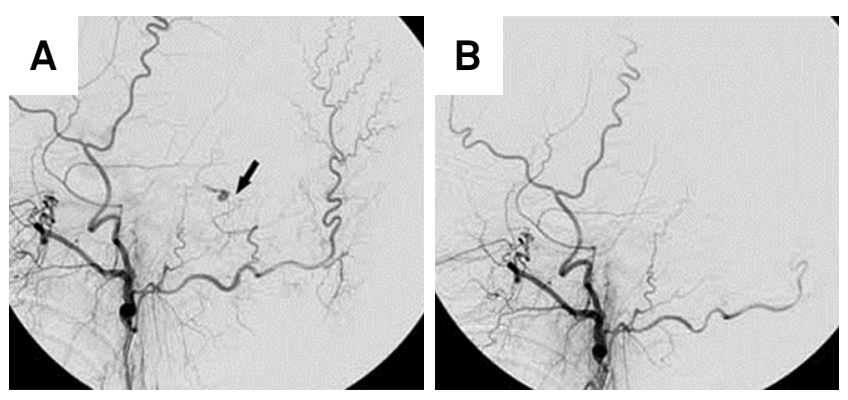

Figure 2. External carotid artery angiogram before (left) and after (right) embolization. Early filling of an intradural vein without a draining pathway (arrow, A) was no longer observed after treatment (B).

\section{References}

1. Stam J. Thrombosis of the cerebral veins and sinuses. N Engl J Med. 2005;352:1791-8. http://dx.doi.org/10.1056/NEJMra042354
2. Ferro J, Canhão P, Stam J, et al. Prognosis of cerebral vein and dural sinus Thrombosis: Results of the International Study on Cerebral Vein and Dural Sinus Thrombosis (ISCVT). Stroke. 2004;35:664-70. http://dx.doi.org/10.1161/01.STR.0000117571.76197.26

\footnotetext{
1 Universidade de São Paulo, Hospital das Clínicas, Divisão de Neurologia Clínica, Sao Paulo SP, Brasil;

${ }^{2}$ Hospital Israelita Albert Einstein, Sao Paulo SP, Brazil;

${ }^{3}$ Universidade de São Paulo, Hospital das Clínicas, Divisão de Radiologia, Sao Paulo SP, Brasil.

Correspondence: Adriana B. Conforto; Universidade de São Paulo, Hospital das Clínicas, Divisão de Neurologia Clínica; Av. Dr. Enéas de Carvalho Aguiar, 255/5080; 05403-000 São Paulo SP, Brasil; E-mail: abconf@usp.br

Conflict of interest: There is no conflict of interest to declare.

Received 20 January 2015; Accepted 11 February 2015.
} 